\title{
LA IMAGEN SOCIAL DEL OFICIO DE HISTORIADOR
}

\author{
The Image Which Society Has Historian's Craft About
}

\author{
Alfonso Manjón Esteban \\ E-mail: chengo_2001@usal.es \\ Universidad de Salamanca
}

Fecha de recepción: 22-II-2011

Fecha de aceptación: 28-III-2011

RESUMEN: A pesar de la evolución que han sufrido los estudios históricos en las últimas décadas, no son demasiadas las aportaciones que los historiadores han hecho acerca de la labor que desempeñan, de las dificultades con que se encuentran a la hora de desarrollar su actividad profesional o de la importancia que adquiere su trabajo intelectual dentro del desarrollo cultural que experimenta la sociedad en la que vive. Esa realidad se ve reflejada en la imagen que la sociedad tiene acerca de su oficio. Así, los problemas con que el historiador se encuentra en su profesión, la escasa difusión de los valores con que debe realizarse el trabajo científico, la escasa presencia que muchas veces los historiadores tienen en los medios de comunicación, así como la más bien deficiente formación teórica y práctica de los estudiantes de Historia en la Universidad, permiten que la sociedad tenga un concepto no demasiado claro acerca, no ya de la importancia de los estudios históricos (lo que a veces también ocurre), sino de la legitimidad y honradez de nuestra labor académica e investigadora.

Palabras Clave: Historiografía, sociedad, Universidad, imagen, valores científicos.

AвSTRACT: Despite the development that historical studies have suffered in recent decades, there are not too many contributions that historians have made about the work they perform, the difficulties they have when they do their job or about the importance that their intellectual work has in the cultural development experienced by the society in which they live.

That reality is reflected in the image that society has our craft about. In this way, the problems which historians have in this work, the scanty diffusion of the values which historians should make their scientific work with, the scanty presence of historians in the mass media, as well as the inadequacy of theoretical and practical education of the students of History in the University, are reasons to think that the society don't have a clear idea 
about, not the importance of History, but the importance about the use the work we do has and the importance of the legitimacy and honesty of our academic work and our researches.

Keywords: Historiography, society, University, image, scientific values.

\section{INTRODUCCIÓN}

Se pregunta Julio Aróstegui en La investigación histórica: teoría y método, cómo puede ser posible que la reflexión acerca de la entidad y la naturaleza de la Historia y de lo histórico la lleven a menudo más bien los filósofos que los propios historiadores. Piensa este autor que es función del historiador "reflexionar sobre la práctica historiográfica y producir «estados de la cuestión», que es a lo que los historiadores acostumbran, [pero también que] es ineludible [por parte de este grupo] repensar la idea misma de Historia; es decir, hacer una reflexión sobre la teoría y no sólo sobre la praxis, por muy importante que ésta sea". ${ }^{1}$

Esta afirmación nos hace ya pensar que en realidad los historiadores venimos trabajando bastante poco en definir cuál es el contorno de nuestra actividad profesional y cuáles son las atribuciones que la Historia tiene o no asignadas en exclusiva. Pero no sólo eso. También nos permite creer que no hemos conseguido definir muy bien (ni por tanto, y lo que es más importante, explicar) qué tipo de conocimiento aporta la Historia, qué utilidad social tiene el conocimiento histórico, ni qué capacidades o habilidades cognitivas aporta su estudio.

Este no es un tema baladí, ni mucho menos. En la definición y explicación de la Historia como disciplina y como realidad de lo histórico, el historiador se juega su propia credibilidad y su propia identidad como intelectual. Más aún en una sociedad como la actual, donde el rol tradicional del historiador se ha visto seriamente cuestionado. El historiador español de hoy no es el actor político del siglo XIX capaz de decidir qué tipo de relato histórico era o no legítimo. Ni es el historiador (también actor político en muchos casos) centrado esencialmente en la nación o en determinados grupos sociales como protagonistas principales del relato histórico, propio del siglo XX. El historiador actual es un intelectual inmerso en una sociedad plural, multicultural, democrática, madura por cuanto alfabetizada y crítica,

1 Aróstegui, Julio. La investigación histórica: teoría y método. Barcelona: Crítica, 2001, pp. 33-34 
y que se enfrenta al éxito de otros formatos de narración histórica (de corte periodístico o literario, relatos de memoria histórica, etc.) menos rigurosos pero que, a menudo, y como ha dicho Pablo Sánchez León, "resultan más sensibles al público que muchos de los sesudos estudios del historiador"'.

Esto no significa que el historiador haya dejado de tener un papel hegemónico dentro de su área, ni que su producción escrita sea menos inteligible para la sociedad (aun por más compleja). Tampoco significa que haya dejado de ser un image-maker social, un agente capaz de decirle la verdad al poder o un agitador de conciencias. Significa simplemente que deberíamos preguntarnos más a menudo cuál es realmente nuestra función en la sociedad y qué papel mantenemos como creadores de un imaginario que contribuye al desarrollo cultural de una sociedad determinada. Significa que deberíamos preguntarnos de qué legitimidad disfrutan nuestros trabajos de investigación (viendo si se cuestiona socialmente nuestra actividad profesional como una actividad sensible a los problemas que se le plantean a la sociedad). Significa también que debemos preguntarnos en qué medida podemos atribuirnos -frente a otras ciencias sociales y otros medios de divulgación histórica y cultural- la potestad del estudio del pasado como raíz de nuestra cultura, de nuestra tradición y de nuestras instituciones; y preguntarnos hasta qué punto nuestra actividad trasciende de los círculos académicos dentro de los cuales nos movemos.

Para ello, lo mejor será plantearnos qué papel ejerce el historiador como intelectual, para después ocuparnos de cuáles son los problemas que se le plantean al mismo dentro de su labor académica.

\section{El HISTORIADOR COMO INTELECTUAL}

Partamos del hecho de que no es fácil definir qué es exactamente un intelectual como tal. El término intelectual proviene del término latino intellectualis, que hace referencia al hombre dotado de inteligencia y, por tanto, al hombre capaz de comprender y resolver los problemas que plantea la realidad.

2 Sánchez León, Pedro: "El ciudadano, el historiador y la democratización del conocimiento del pasado". En Sánchez León, Pedro; Izquierdo Martín, Jesús. El fin de los historiadores. Pensar históricamente en el siglo XXI. Madrid: Siglo XXI, 2008, p. 141. 
El intelectual es así aquella persona que ha sido debidamente formada, instruida académicamente, que en numerosas ocasiones tiene además determinada relevancia pública, y que tiene capacidad para escoger una de las diferentes alternativas que se plantean a cada problema que se le presenta ${ }^{3}$.

Esa posibilidad de elección ha hecho que tradicionalmente se haya venido afirmando que el intelectual, al enjuiciar la realidad según una determinada opción o comprensión del mundo, base su posicionamiento en una adscripción o afinidad ideológica, moral o grupal específica. Esto hace, en consecuencia, que el contenido de la actividad que desarrolle cada intelectual, así como el pensamiento que se contenga en su obra, determinen el sentido de su aportación social y cultural. Razón ésta por la que nos encontramos directamente con un concepto bastante plural de la figura del intelectual.

Sin embargo, a lo largo de las siguiente líneas, es nuestra intención trazar la imagen del intelectual como una figura a la que reduciremos a una forma convencional, abstracta, equiparable a todas las ideologías e intereses, aunque éstos constituyan en definitiva el elemento socializante.

Señalábamos, por tanto, que el intelectual ha aparecido como un agente parcial, que habla a un público determinado, lo cual ha hecho que tome vigor esa definición que Edward Said hiciera del intelectual como "un individuo dotado de la facultad de representar, encarnar y articular un mensaje, una visión, una actitud, filosofía u opinión para y en favor de un público"4.

Más allá de esta cuestión, el intelectual es un agente encargado de hacer progresar la ciencia con sus estudios, con sus reflexiones. Y en la medida en que se logra esto, sobre todo en aquella rama de la Ciencia ligada al estudio del espiritu, de la realidad social, nos damos cuenta de que ese progreso se traduce en la creación de discursos que incorporan opiniones, valores e ideologías que ordenan y organizan nuestra interpretación de la sociedad en la que vivimos. Hay que señalar, no obstante, que este fenómeno no sólo se da a nivel ciudadano, sino también a nivel profesional, ya que el progreso de la ciencia también tiene como objetivo la formación y la incentivación de las

$3 \mathrm{El}$ intelectual es, por tanto, una persona dotada de inteligencia, por cuanto inteligente deriva de los términos inter (entre) y legere (escoger o leer).

4 Said, Edward. Representaciones del intelectual. Barcelona: Paidós, 1996, pp. 29-30. De esta forma, señala que "los intelectuales representan algo para sus audiencias, y al hacerlo así se representan a sí mismos y para sí mismos”. Ibíd., p. 16. 
potencialidades individuales de otros intelectuales, lo cual es también fruto del compromiso social de quien hace evolucionar dicha ciencia.

Esos discursos de los que hemos hablado, además, pueden tener mayor o menor repercusión pública dependiendo de la divulgación que se dé a cada uno de ellos. Y pueden tener mayor o menor acogida en la sociedad y en el ciudadano medio dependiendo del estado de opinión generalizada del país, de la normalidad institucional con que se desenvuelvan los órganos políticos y administrativos de la nación, o del conjunto de interpretaciones que los intelectuales hayan dado al problema concreto de que nos ocupemos. Pero en términos generales, podemos afirmar que son ellos los encargados de generar opinión y, por tanto, de hacer evolucionar o transformar la imagen que se tiene de nuestra cultura y de nuestros valores como comunidad ${ }^{5}$. Esta transformación se verá directa o indirectamente reflejada en el comportamiento diario y en el pensamiento de los ciudadanos, capaces a su vez de generar opinión y conductas sociales. Antonio Gramsci decía:

"No hay actividad bumana de la que se pueda excluir toda intervención intelectual, no se puede separar el homo faber del homo sapiens. Cada hombre, considerado fuera de su profesión, despliega cierta actividad intelectual, es decir, es un "filósofo", un artista, un hombre de buen gusto, participa en una concepción del mundo, tiene una consciente linea de conducta moral, y por eso contribuye a sostener o a modificar una concepción del mundo, es decir, a suscitar nuevos modos de pensar".

Una vez entendido esto, podemos subrayar alguna de las funciones que les está encomendadas al intelectual y, por ende, al historiador. Funciones que, como decimos, servirán como elementos de socialización.

Una de esas funciones del intelectual es la de ser un agente legitimador del poder o capaz de contradecirlo. Edward Shils decía que los intelectuales "o están en contra de las normas dominantes, o bien, de una manera básicamente acomodaticia, trabajan para ofrecer «orden y continuidad

5 En este sentido, los historiadores tienen una función muy definida: la conservación, provecho y utilización del patrimonio histórico.

6 Gramsci, Antonio. Los intelectuales y la organización de la cultura. Buenos Aires: Nueva Visión, 1997. 
en la vida pública»" ". En España, durante los siglos XIX y XX, hasta la instauración de la dictadura franquista, el intelectual se adscribió a una determinada bandería o partido político según su inclinación ideológica. Con la Guerra Civil y la subida de Franco al poder se produjo una fractura intelectual que llevó a medio país (intelectualmente hablando) al exilio. Los intelectuales de dentro se limitaron muchas veces a hacer su trabajo como buenamente pudieron, aprovechando los limitados y progresivos medios de que fueron disponiendo, y sin molestar demasiado al régimen; pero en numerosas ocasiones, hubo también quienes participaron de la acción represiva e ideológica del Estado, legitimándolo así. La muerte del dictador y la instauración de la democracia cambiaron el rol y las posibilidades de esta figura (entendida abstractamente). Es cierto que durante los casi cuarenta años de dictadura existió la figura del intelectual comprometido con la lucha antifranquista, una figura que obraba con autonomía -y bajo la mirada atenta del régimen- en ámbitos cerrados; pero la transición dotó al intelectual de ese halo de libertad que le faltaba. En este contexto, se puede entender que, como decía Raymon Aron, al intelectual no le importara otra cosa más que "que el Poder le dejase [sic] el derecho de reflexionar, de criticar; que no le infligiese [sic] la obligación de exaltar lo real"8. Y en este escenario post-dictatorial, encontramos la figura del intelectual como agente comprometido con ciertas causas, pero preocupado por el individuo (no sólo por el colectivo) ${ }^{9}$ e inmerso en una sociedad plural y democrática que le ha hecho tomar una perspectiva alejada del poder; una perspectiva que le permite enjuiciarlo con ponderación. Así pues, el intelectual se convierte en el primer agente encargado "de cuestionar el nacionalismo patriótico, el pensamiento corporativo, y el sentimiento de superioridad clasista, racial o sexual"

7 Shils, Edward: "The intellectuals and the Powers: Some Perspectives for Comparative Analysis". En VVAA. Comparative Studies in Society and History, vol. I. (1958-1959). London: Cambridge University Press, 1958-1959, pp. 5-22. En Said, Edward. Representación, pp. 5051.

8 Aron, Raymon. Dimensiones de la conciencia histórica. Madrid: Tecnos, 1962, p. 207.

9 Hemos de tener en cuenta el giro historiográfico que se produce en los años 70 .

10 Said, Edward. Representación, p. 15. Considero este libro una referencia importante en lo que se refiere al papel del intelectual como agente capaz de cuestionar el poder y la práctica del poder. En otra página (p. 40) el autor dice: "No se trata de cuestionar siempre la política del gobierno, sino más bien de la vocación intelectual como actitud de constante 
individuo duro, elocuente, inmensamente valiente y aguerrido para quien ningún poder mundano es demasiado grande e imponente como para no criticarlo y censurarlo con toda intención" ${ }^{\prime 1}$. El historiador, en este sentido, actúa denunciando las manipulaciones políticas y los usos ideológicos que se puedan hacer del pasado. Veremos esto más adelante cuando hablemos del método.

En segundo lugar, el intelectual ejerce de image-maker social. Es el creador de un imaginario que reconstruye o redefine la realidad social en que vive. Esta cuestión es importante por cuanto "la conducta humana depende de la imagen, [y por cuanto] los sistemas sociales son orientados por imágenes" ${ }^{\prime 12}$. El papel del historiador es, en este terreno, significativo por cuanto no se dedica exclusivamente a analizar el pasado sino a entender el mundo en el que vive desde la comprensión de la evolución del pasado. En este sentido, el historiador, al conferir un determinado sentido a ese mundo dentro del cual se desenvuelve de acuerdo a unas pautas o interpretaciones históricas concretas, no hace sino crear un imaginario sobre el que se asienta la cultura, que a la postre es la que determina en buena medida la acción humana ${ }^{13}$. No obstante, debido a la importancia de este hecho y a la existencia de diferentes interpretaciones históricas de la realidad, hay quien ha dicho recientemente que "historiadores y estudiosos están obligados, cuando menos, a ser más autorreflexivos y modestos en sus pretensiones de conocimiento de esa realidad y, por consiguiente, más cautos, prudentes y precavidos a la hora de hacer recomendaciones e intervenir en el terreno de la práctica" ${ }^{\prime 14}$.

vigilancia, como disposición permanente a no permitir que sean las medias verdades o las ideas comúnmente aceptadas las que gobiernen el propio caminar".

11 Ibíd., p. 27.

12 Marsal, Juan F. Pensar bajo el franquismo. Intelectuales y politica en la generación de los años cincuenta. Barcelona: Ediciones Península, 1979, p. 36.

13 El historiador es capaz de cambiar la conciencia histórica y los prejuicios que el ciudadano tiene respecto de alguna parte de su realidad, y le ayuda a entender el poliformismo de la historia humana. Miguel Ángel Cabrera ha dicho que "junto con las denominadas ciencias sociales, la historia ha operado como una de las correas de transmisión entre el imaginario moderno y la acción humana". Cabrera, Miguel Ángel: "La historia y los historiadores tras la crisis de la modernidad”. En Sánchez León, Pedro; Izquierdo Martín, Jesús. Fin, p. 48.

14 Ibíd., p. 55. 
El intelectual ejerce, además, de guía social. La razón de ello radica en que nadie como él puede interpretar globalmente la sociedad en la que vive, y nadie como él puede ser guardián de una cultura, y de la tradición y de la Historia de un país. Por eso ha de tomar como cometido ejercer de figura capaz de decirle la verdad al poder, de guía capaz de llevar a cabo procesos de concienciación social ineludibles, o ejercer como cabeza de protesta ante la injusticia. Álvaro Ferrary ha sostenido que esto es así "a causa de sus elevados niveles de conocimiento, de su finura cultural y, por tanto, de sus superiores facultades racionales" ${ }^{\prime 15}$.

La figura del historiador juega a este respecto un papel igualmente importante. Para empezar, hay que señalar que como ha dicho José María Mínguez, el historiador ha de sentir un papel de especial y exigente responsabilidad en el devenir de la civilización actual, ya que éste, desde "el observatorio privilegiado en que se encuentra, desde el conocimiento de las claves elementales para la interpretación del comportamiento de las sociedades pretéritas y, al mismo tiempo, desde su inserción preocupada en la sociedad en que vive, $[\ldots]$ no sólo está legitimado para realizar un análisis particularmente certero de la sociedad actual, sino que además cuenta con medios de intervención en ella tan poderosos que la utilización irresponsable de los mismos puede arrastrar graves consecuencias" ${ }^{\prime 16}$. Esa responsabilidad la ha de ejercer actuando como conciencia crítica de la sociedad, desenmascarando "las mistificaciones ideológicas de la realidad y socavando [sic], de ese modo, las relaciones de dominación basadas en ellas"17. De esta forma, lo que hace el historiador es enseñar al mundo a mantener una actitud crítica, a construir posibilidades interpretativas que les lleve a entender mejor la realidad que vive, y a transformar de ella lo inservible. Lo hace dotando al público de conciencia histórica, por la cual el sujeto es capaz de analizar y valorar el pasado y el presente atendiendo

15 Ferrary, Álvaro: “"La mirada intelectual de ver las cosas»: exploración abierta a la figura del intelectual contemporáneo”, en Memoria y civilización, no 2 (1999), p. 297.

16 Mínguez, José María. La historia y el historiador ante la sociedad. Salamanca: Ediciones Universidad de Salamanca, 2010, pp. 34-35.

17 Cabrera, Miguel Ángel: "La historia y los historiadores..., p. 56. Y añade: "El conocimiento histórico debía ser utilizado para identificar y neutralizar los dispositivos ideológicos que se interponían entre la realidad y la conciencia, con el fin de conseguir que la práctica humana estuviera en consonancia plena con su supuesta esencia, fuera ésta natural o social”. Ibíd., p. 56. 
a su propia experiencia histórica personal, y actuando socialmente en consecuencia según estime oportuno.

Creemos que este papel del historiador como guía social capaz de dotar al ciudadano de una conciencia histórica y de una actitud crítica es bastante revelador de la función social que éste tiene asignada. Entre otras cosas, porque al ejercer dicha función lo que consigue fundamentalmente es que el ciudadano tenga una idea más clara de las posibilidades históricas de su existencia y, por tanto, una idea más clara del presente y del porvenir. Es indudable, en este sentido, que el futuro es siempre un ente incierto y expuesto a una serie de factores capaces de alterar el curso natural de la evolución humana. Pero, no obstante, es evidente también que un conocimiento más exhaustivo e histórico del presente y del pasado nos permite comprender mejor la racionalidad y las causas de la aparición de ciertos comportamientos sociales, nos permite interpretar las tendencias sociales que acontecen, prever qué opciones son probables y posibles mañana (no hablamos de determinismo histórico) ${ }^{18}$, y liberarnos del pasado y no caer rutinariamente en antiguos errores (lo cual no indica que estemos exentos de caer en errores de nuevo cuño). José Antonio Maravall ha escrito:

"La Historia nos libera, pues, de los errores pasados y también de los presentes en la medida en que dependen de la berencia recibida. Pero quizá lo más justo sería decir que nos libera de esos errores para permitirnos caer en otros. La Historia no es nunca solución. En el laberinto de dificultades en que cada circunstancia consiste no nos revela jamás la salida $[\ldots]$

La Historia no es un repertorio de soluciones ni mucho menos de sistemas. Lo es, en todo caso, de problemas, y hasta lo que un día pareció solución válida para cualquiera de éstos, luego queda más bien como la forma de un error. Por eso la Historia es una serie de tentativas, de ensayos" ${ }^{19}$.

\footnotetext{
18 Hay que señalar en este sentido cómo ha quedado atrás la antigua polémica sobre la "legalidad natural" de la Historia, esto es, sobre la infalibilidad de aquellas leyes históricas capaces de predecir el futuro por el conocimiento de ciertos fenómenos ocurridos en el pasado. En el mundo griego, ya Tucídides hablaba de la Historia como un sistema cerrado de causación, constante y uniforme, basado en leyes, y por el cual, a unos mismos fenómenos le siguen unas mismas consecuencias. Bernheim interpretó este postulado en su teoría de una "Historia genética".
}

19 Maravall, José Antonio. Teoría del saber histórico. Madrid: Revista de Occidente, 1958, pp. 
Aparte de esa función de guía social, el intelectual tiene asignada una misión moral". Es el "insobornable moralista de nuestro tiempo" 21 , como dijo Aranguren. Moralista no en el sentido de dotar al ciudadano de valores trascendentes o metafísicos (lo cual sucede también en muchos casos), sino en el sentido de "alumbrar nuevos proyectos, [y] proponer nuevos modos de ser y vivir" 22 , lo cual tiene mucho que ver con la creación de imágenes de la que hemos hablado más arriba.

La función del historiador en este sentido es también notable, debido a que éste es capaz de conocer y entender mejor que nadie los valores pretéritos y presentes que definen y han definido a la nación. Al describir, comprender y explicar el pasado, no hace sino crear patrones estructurales de transformación histórica y enriquecer una visión del presente por medio de la creación de analogías entre ambos (bistoria magistra vitae est), sin necesidad por ello de mantener una visión estática y permanídica del mundo y de la historia (concepto de repetibilidad). La Historia sirve, pues, para preservar la memoria y los valores del pasado (cerrando heridas) ${ }^{23}$, pero también para crear valores sociales capaces de modificar la misma identidad social y fomentar entre los ciudadanos sentimientos de pertenencia ${ }^{24}$.

El intelectual (y el historiador) actual debería tener además como función la de representar un papel de mediador y de traductor entre las diversas manifestaciones culturales e ideológicas de un país. Por un lado, entre aquellas culturas distintivas, nativas digamos, de un mismo país ${ }^{25}$. Pero por otro lado

\section{1-252.}

20 Algunos autores como Peter Mandler no están de acuerdo con esta teoría, y piensan que los historiadores no son quiénes para dar lecciones morales y ejercer de brújula moral de la sociedad. Ver Mandler, Peter: "La responsabilidad del historiador", en Alcores. Revista de Historia Contemporánea, $\mathrm{n}^{\circ} 1$ (2006), pp. 47-61.

21 López Aranguren, José Luis. La cultura española y la cultura establecida. Madrid: Taurus, 1975 , p. 236.

22 Marina, José Antonio: “Un intelectual en busca de una ética”, en Isegoría, no 15 (1997), p. 121.

23 La memoria no como entendimiento subjetivo de la Historia (ya que la Historia ha de tender a corregir las ficciones de ese relato), sino como sujeto de lo ocurrido.

24 Esta cuestión es importante por cuanto nos ayuda a entender la forma en que un individuo toma conciencia de esa pertenencia, la evalúa emocionalmente, y se siente integrado en un grupo. Eso genera en él bienestar y autoestima.

25 En este sentido, afirma Jörn Rüsen que muchos historiadores "se creen responsables 
también, entre aquellas culturas venidas de fuera. Así, cabe decir que en una sociedad democrática, el intelectual debería transmitir a la sociedad una imagen más cercana de aquellas culturas y pensamientos que nos resultan más extraños, de modo que podamos conseguir una toma de contacto y un entendimiento mutuo entre partes diferenciadas. En esta función, el historiador debería tomar un papel preeminente en el debate público, pues su mayor conocimiento de la Historia de aquellas civilizaciones que -en continuo movimiento- han dejado a su paso numerosas huellas en la cultura del país, hace que éste sea un agente capaz de comunicarse mejor con esas culturas, de "entrar en su personalidad, ver con su mirada, experimentar con su sensibilidad, [y] juzgar según sus criterios"26.

Finalmente, el intelectual debería intervenir en sociedad regulando conductas. Álvaro Ferrary señala que son estas minorías ilustradas las encargadas de "percibir los inevitables conflictos y tensiones de la realidad social a modo de meras desviaciones patológicas"27. Por lo que cabe deducir que son igualmente ellas las encargadas de corregir dichas patologías. El intelectual es, debido a su mayor clarividencia respecto de los acontecimientos sociales, una especie de juez capaz de dirimir en cada momento qué es lo correcto y qué no lo es, de acuerdo al transcurso normal de las cosas y de las posibilidades que ofrecen los tiempos. Esto no es óbice para que su interpretación no sea siempre acertada, ni mucho menos para que se cumpla, pero nadie como él puede a priori juzgar la realidad con mayor sobriedad. Además, y debido a

de haber librado a la identidad nacional de sus ataduras tradicionales, uniformidad y agresividad (hacia dentro y hacia fuera) para favorecer una relación más abierta a las diferencias culturales en un sistema político dado". En Rüsen, Jörn: "Responsabilidad e irresponsabilidad en los estudios históricos", en Alcores. Revista de Historia Contemporánea, no 1 (2006), p. 33.

26 Prost, Antoine. Doce lecciones sobre la historia. Valencia: Frónesis, 1996, p. 169. En este sentido M.A. Cabrera ha afirmado que "El historiador no es tanto el juez de las disputas como un generador de las capacidades que permiten participar, con sensibilidad y conciencia histórica críticas, en tales debates públicos, en el entendimiento de que el libre debate enriquece la democracia y resulta vital para ésta, y de que, por el contrario, la existencia de identidades exclusivistas sin debate entre ellas es indeseable por amenazar el pluralismo". En Cabrera, Miguel Ángel: "La historia y los historiadores..., p. 250. Lo que es evidente es que la Historia debería contribuir como disciplina que lucha contra la intolerancia, ya que el conocimiento de lo ajeno nos ayuda a entenderlo sin despreciarlo directamente.

27 Ferrary, Álvaro: “«La mirada intelectual de ver las cosas»”, p. 302. Hay que señalar que el autor nos habla de otro contexto diferente del que nosotros nos ocupamos (finales del siglo XIX-primeros del XX), pero su afirmación nos sirve en este caso. 
ciertos condicionamientos, puede darse el hecho de que la interpretación que varios intelectuales den a un mismo problema difiera notablemente. Esto es así, entre otras cosas, porque como dijera uno de los filósofos españoles más importantes del siglo XX, Xavier Zubiri, "el hombre no puede agotar la riqueza de la realidad, sino que es inacabable radicalmente, a saber, porque la realidad en cuanto tal es desde sí misma constitutivamente abierta"28.

\section{El historiador y El PROBLEMA DEONTOLÓGICO DE LA Historia}

En realidad, más allá de la mera teoría acerca de la función del historiador como intelectual capaz de influir en los procesos de desarrollo cultural de la sociedad, éste se enfrenta a problemas que tienen que ver con la teoría, metodología y epistemología de su propio oficio. Problemas que definen su labor como investigador y que influyen directamente en la imagen social que de él tiene la sociedad en general. Para entender qué problemas son esos, debemos preguntarnos qué tipo de trabajo realiza el historiador y qué tipo de factores inciden en él, elementos ambos que determinan en buena medida la imagen y la confianza que la sociedad tiene puesta en nuestra profesión.

\subsection{La visión social del método historiográfico}

Empezaremos señalando cómo hasta la fecha se ha venido cuestionando dentro del mundo universitario, académico y científico, la existencia de una metodología propia del historiador. Muchas han sido las personas que han entendido y entienden que los historiadores han tomado prestado su corpus teórico y metodológico de otras disciplinas enmarcadas dentro de las ciencias sociales (lo que no hace sino cuestionar la dependencia de la Historia respecto de estas disciplinas, y el monopolio del conocimiento y explicación del pasado ejercido por los historiadores). No obstante, la Historia ha ido evolucionando de forma autónoma, y ha tomado, respecto de otras áreas de las ciencias humanas, los factores espacio y tiempo como premisa desde la cual parte toda su actividad ${ }^{29}$. Nadie como la Historia, salvo en cierta

28 Zubiri, Xavier: "Sentido de la vida intelectual (Discurso del premio «Ramón y Cajal» a la investigación científica (1982)", en Anthropos: Huellas del conocimiento, no 201 (2003), pp. 37-38.

29 En un reciente homenaje (22/02/2011) que la Universidad de Salamanca ha hecho a Julio Aróstegui con motivo de su jubilación, este prestigioso historiador dijo que la Historia se diferenciaba de estas disciplinas sociales lo mismo que se diferencia una fotografía de 294 
parte las Ciencias de la Geografía, maneja con mayor soltura dichas variables a la vez. Y en numerosos casos, nadie como ella opera con mayor habilidad entrelazando las diferentes variables que determinan la evolución histórica desde una perspectiva tan pluralista (bajo estudios de corte nomotético o de corte idiográfico ${ }^{30}$ ). A diferencia de lo que ocurre muchas veces en otras disciplinas, la Historia acostumbra a trabajar con los diferentes factores que interactúan en dicha evolución histórica: económicos, demográficos, sociológicos, antropológicos, politológicos, etc. ${ }^{31}$; lo cual no quiere decir que no existan dentro de nuestra actividad una serie de enfoques o fuerzas motrices que determinen el sentido de las investigaciones que se llevan a cabo: ya sean esas fuerzas de corte materialista o idealista, ya tengan en cuenta antes al individuo o las estructuras sociales (holismo). Pero muchas veces los estudios históricos procuran hacer un ejercicio de interrelación de ambas opciones, llegando a lo que Mario Bunge ha venido a denominar "sistemismo histórico"32.

Por otro lado, y dejando de lado los enfoques que pueda adquirir la investigación histórica, hay que decir que el armazón metodológico de la Historia se fundamenta en la búsqueda de fuentes, en el examen de documentos o restos históricos, en la formulación de preguntas históricas, y en la crítica posterior a las fuentes (investigación y sistematización). En ese sentido, la formación recibida y la experiencia acumulada por el historiador constituyen la defensa más sólida que se pueda hacer del trabajo que éste desempeña.

Para empezar, diremos que han sido varios los autores (Topolsky, L. Genicot, J. Aróstegui, etc.) que han venido estableciendo diferentes tipologías de fuentes. No entraremos en detalles, porque hacerlo supondría alargar innecesariamente este artículo. No obstante, diremos que su estudio

un video, ya que la Sociología, por ejemplo, nos muestra la fotografía de un momento concreto, mientras la Historia se basa en secuencias.

30 La visión nomotética es la que se basa en estadísticas y la idiográfica la que hace énfasis en la experiencia individual.

31 Como ha dicho Mario Bunge: "Los "factores" (condiciones, sucesos o procesos) ambientales, biológicos (en particular demográficos), económicos, políticos y culturales se alternan como iniciadores del cambio social, y se influyen mutuamente". En Bunge, Mario. Las ciencias sociales en discusión: una perspectiva filosófica. Buenos Aires: Editorial Sudamericana, 1999, p. 293.

32 Ibíd., p. 302. 
y sistematización han ayudado mucho al investigador (especialmente al investigador neófito) a conocer cuáles son esas fuentes y a cómo manejarlas. El uso correcto y crítico de dichas fuentes es una labor que el historiador es capaz de realizar con especial rigor, ya que en principio es quien mejor puede llevar a cabo una crítica externa e interna del documento con que se enfrenta. Y por tanto, quien mejor puede hacer un análisis serio de la información en él contenida. No sólo por la razón anteriormente aludida, sino porque el historiador estudia Historia a tiempo completo, y porque atesora un conocimiento previo del tema sobre el que investiga que le capacita a observar dichas fuentes con una profundidad mayor que con la que otros investigadores de otras áreas podrían hacerlo.

Este es un elemento importante que permite que el oficio de historiador goce de una notable legitimidad social. Sin embargo, el problema lo encontramos cuando la sociedad observa que las interpretaciones que hacemos de los documentos observados difieren considerablemente en las conclusiones a que llegan los diferentes historiadores. ¿Qué elemento de justificación encuentra la Historia a este respecto? Fundamentalmente, esta realidad se explica y se justifica socialmente si conseguimos hacer ver que la observación de las fuentes depende en gran medida de las preguntas históricas que les haga el historiador y, por tanto, que dependiendo de esas preguntas, los documentos nos hablarán de unas cosas u otras. Además, hay que señalar en ese sentido, que socialmente ha de entenderse que no son sino los historiadores quienes se sienten mejor capacitados para hacerles preguntas a los documentos, y también para encontrar las respuestas dentro de esos documentos, debido, como hemos ya apuntado, a que son los profesionales de la Historia quienes atesoran un conocimiento mayor sobre la realidad de la que nos hablan las fuentes. Robin G. Collingwood lo define de la siguiente manera:

\section{"Mientras más conocimiento bistórico poseemos,} más podemos aprender de cualquier testimonio histórico determinado; si no poseyéramos ninguno no podríamos aprender nada. El testimonio histórico es testimonio bistórico solamente cuando alguien lo considera históricamente" ${ }^{33}$.

33 Collingwodd, Robin G. The Historical Imagination. An Inangural Lecture delivered before the University of Oxford on 28 october 1935. Oxford: Clarendon Press, 1946, p. 16. En Prost, 
En este orden de cosas, hay que apuntar que las preguntas que se hagan a las fuentes así como la interpretación de lo que éstas últimas contienen, dependen en buena medida de la crítica que se haga de ellas. Este nos parece igualmente un factor de legitimación social importante de nuestra profesión, ya que la crítica es el elemento central de nuestro trabajo. Por ello, pensamos que el mayor conocimiento de cómo se lleva a cabo esa crítica conduciría a que la labor que desarrollamos sea bien recibida en la sociedad. En este sentido, cabe destacar que la crítica histórica tiene unas reglas concretas, y que es evidente que el buen empleo de esas reglas depende siempre tanto de su conocimiento como de la experiencia acumulada de quien las aplica. Así, de nuevo es el historiador quien goza de ese conocimiento, quien trabaja a tiempo completo, y quien adquiere por tanto una clarísima ventaja frente a otros estudiosos de la Historia, ya sean eruditos, periodistas o novelistas. Lo hace porque "la crítica, la propia historia, se afina a medida que la historia se amplía y profundiza" 34 , lo que provoca que el historiador se sienta más capacitado para poner en cuestión tanto la veracidad de la información que contienen las fuentes (coherencia interna y coherencia respecto de lo que nos dicen otros testimonios) como la legitimidad de las fuentes mismas como documento histórico (características materiales de la fuente, etc.).

\subsection{Los agentes condicionantes del oficio de historiador: la actitud del historiador.}

Una vez analizada la importancia del historiador en la aplicación del método frente a otros estudiosos (habría que haber hecho mayor hincapié en los criterios de selección de fuentes y en el modo de elaboración de toda la información histórica en ellas contenida), debemos señalar que existen una serie de condicionantes que inciden en el trabajo del historiador y que determinan igualmente el concepto que la sociedad tiene de nuestra labor académica y de nuestra función social. Estos condicionantes se dividen fundamentalmente en dos: en primer lugar, la actitud del historiador frente a las fuentes y el relato histórico, y en segundo, los valores que debieran regir la investigación histórica.

En lo que se refiere al primero de esos dos elementos (la actitud

Antoine. Doce lecciones, p. 93.

34 Prost, Antoine. Doce lecciones, p. 70. Señala este autor que las reglas de la crítica "tienen la función de educar la forma en que el historiador mira las fuentes. Una gran virtud si se quiere, en todo caso una actitud aprendida, no espontánea, pero que moldea el carácter esencial de aquellos que se dedican a este oficio”. Ibíd., p. 76. 
del historiador), cabe señalar que ésta viene determinada por una serie de variables que tienen que ver casi siempre con su propia personalidad.

En primer lugar, entendemos que la motivación que lleva al estudiante y después al profesional a dedicarse por completo al estudio de la Historia depende en buena medida del grado de preocupación social y cultural, y de la inquietud intelectual que éste posea. No siempre es así. No siempre el estudiante de Historia tiene vocación de historiador ni pretende hacer de la Historia el objeto de su futuro profesional. Pero normalmente, como bien dice Antoine Prost, al que ya hemos citado anteriormente, la historia es un trabajo sobre uno mismo, uno es lo que escribe, y "nadie [sic] dedica días o años a estudiar filosofía, literatura o historia a menos que tengan un significado personal. No creo [concluye] que podamos ser buenos historiadores sin una pizca de pasión, signo a su vez de una fuerte apuesta personal" 35 .

Por otro lado, el relato del historiador es siempre hijo de la personalidad y la experiencia personal del autor. Este es un elemento muy importante de cara al relato que se construya, ya que los resultados que obtengamos en nuestras investigaciones siempre tendrán que ver con las preguntas históricas que se formulen a las fuentes. Esto es lo que se da en llamar el "arraigo personal de las preguntas históricas", que a su vez muchas veces dependen del estado de cuestiones que se plantee la sociedad en que viva el autor. Arnold J. Toynbee dijo: "Al mirar al pasado no podemos prescindir de nuestras propias experiencias, acciones, pasiones y prejuicios" 36 .

Los prejuicios (que dependen de esa experiencia personal) son precisamente el tercer elemento en discordia. En la labor historiográfica suele influir el posicionamiento ideológico del autor, condicionado muchas veces por los compromisos morales, religiosos, políticos, etc. que éste haya contraído socialmente. Deberíamos preguntarnos hasta qué punto es legítimo que esos prejuicios sean la base desde la que se construye el relato histórico. La respuesta no sería fácil. En primer lugar porque los prejuicios son el fondo desde el que se formulan las preguntas históricas que, a su vez, nos conducen al cimiento del relato. En segundo lugar, porque prejuicio y honestidad científica no tienen por qué ser elementos enfrentados sino

35 Prost, Antoine. Doce lecciones, p. 106.

36 Toynbee, Arnold J.: "La inaprehensibilidad de la historia. Una reflexión sobre el historiador y el historiado", en Ateneo, no 77 (feb. 1955), p. 4. 
complementarios -recordemos que la Historia es siempre una disciplina abierta- ${ }^{37}$. Y en tercer lugar, porque "es tomando [el historiador] conciencia de su prejuicio como la historia comienza a convertirse en realmente crítica y como se distancia (en la medida de lo posible) de las fantasías de la ficción" ${ }^{38}$.

La última variable dentro de lo concerniente a la actitud del historiador es el hecho de que éstos no pueden dejar de ser nunca hijos de su tiempo. El historiador no es alguien ajeno a la sociedad en la que vive (escribe bic et nunc); sus puntos de vista son en sí mismos históricos; y los problemas que se plantea no son problemas que no interesen al presente y que busquen simplemente el conocimiento por el conocimiento (juzgando al pasado sólo desde el pasado), sino todo lo contrario. José Javier Ruiz Ibáñez, profesor en la Universidad de Murcia, lo describe de la siguiente manera:

$$
\text { "[...] el historiador no trabaja sobre el pasado, }
$$
trabaja sobre el presente, sobre las cuestiones que él y la comunidad cientifica formulan y busca comprenderlas en el pasado. Para [sic] ello propone hipótesis, moviliza técnicas, busca similitudes y realiza enunciados que buscan tener elementos de veracidad; elementos que puedan servir a otras personas para comprender mejor ese pasado y a otros historiadores para mejor aproximarse a otros pasados'39.

Esta es una de las razones por las que hemos dicho que la historia siempre se rescribe: los historiadores siempre miran el pasado porque les preocupa su presente ${ }^{40}$.

37 Ver apartado sobre honestidad científica. ¿Aniquilan los prejuicios la objetividad?

38 Bradley, Francis H. Les Présupposés de l'histoire critique. París: Les Belles-Lettres, 1965, p. 108. En Prost, Antoine. Doce lecciones, p. 154

39 Ruiz Ibáñez, José Javier: "El pretérito no es un presente imperfecto... Algunas consideraciones personales sobre la posición del historiador ante los usos públicos de la historia”. En Nicolás, Encarna; Gómez, José A. Miradas a la bistoria. Reflexiones historiográficas en recuerdo de Miguel Rodríguez Llopis. Murcia: Universidad de Murcia, 2004, p. 96.

40 Toynbee dijo lo siguiente: "La visión del historiador está condicionada siempre en todas partes por su propia ubicación en el tiempo y en el espacio y como el tiempo y el espacio están cambiando continuamente, ninguna historia, en el sentido subjetivo del término, podría ser nunca un relato permanente que narre de una vez para siempre todo, de una manera tal que sea aceptable para los lectores de todas las épocas, ni siquiera para los de todas 


\subsection{Los agentes condicionantes del oficio de historiador: la legitimidad social de los valores de la ciencia histórica.}

Una vez analizada la actitud del historiador como agente capaz de condicionar la imagen social que se tiene de la labor historiográfica, pasemos al análisis de los valores que debieran regir la ciencia histórica, los cuales condicionan también la imagen que la sociedad tiene de nuestro oficio.

El primero de ellos tiene mucho que ver con esto último de que hemos hablado: de la figura del historiador como hijo de su tiempo. Nos referimos al tema de la perspectiva que el historiador adopte respecto del pasado. El investigador tiene dos opciones: o bien se pone en la piel de los protagonistas del tiempo que estudia, o bien se distancia de ellos y los observa desde su propia realidad presente. La opción que tome se distinguirá tanto en la narración del relato, como en la forma de enjuiciar a esos protagonistas de la Historia ${ }^{41}$, así como en los términos conceptuales que emplee (terminología histórica que desvirtuará o hará fidedigna la imagen que se dé del pasado ${ }^{42}$. Y la legitimidad de esa opción dependerá tanto de las formas con que se aborde el estudio como de los fines que se persiga en la investigación. Así habría que diferenciar cuándo un trabajo busca sólo descubrir asépticamente la verdad y cuándo se persigue justificar históricamente y desde una determinada posición un problema presente. En este sentido, cuanto más fiel sea el historiador al método y a los valores de la ciencia histórica que en este apartado resumimos, de más legitimidad gozará la profesión.

El segundo hace referencia a la imparcialidad con que el historiador desarrolle sus trabajos de investigación o a la lectura judicial que haga de la historia. Como señalábamos más arriba, una de las funciones del intelectual es la de ejercer de guía moral. Sin embargo, esa función ha de realizarse sin dejarse llevar por las pasiones personales de cada uno. Ante todo, el historiador ha de mantener una postura ética, en la que represente o tenga

las partes de la Tierra.”. En Toynbee, Arnold J.: “La inaprehensibilidad..., pp. 3-4.

41 Por un lado, poniendo en tela de juicio su actitud. Por otro, mostrándoles ante realidades extrañas a su época. Ruiz Ibáñez nos habla de ver si los historiadores hacen un intento de "respetar a sus protagonistas, a todos sus protagonistas y hacer un esfuerzo por no dotarles de cualidades, deseos o racionalidades que les podían resultar extrañas”. En Ruiz Ibáñez, José Javier: "El pretérito..., p. 96.

42 Pongo un ejemplo: no se puede denominar como obrero a un campesino de la Edad Media. 
en cuenta las posiciones de todo el público al que se dirige. El hecho de que su obra ejerza una función social o moral, no quiere decir que el historiador tenga directamente que dar conscientemente lecciones morales. Su primer cometido es la de observar y comprender el pasado. Y en ese sentido el historiador ha de tender siempre a la imparcialidad, sea cual sea luego el resultado de sus trabajos, que dependen siempre del análisis crítico que haga de las fuentes y de las preguntas históricas que formule a éstas.

La imparcialidad nos la darán, más allá de esa postura ética, los años de trabajo. Y nos la dará la bonestidad con que hayamos trabajado. Como venimos repitiendo a lo largo de estas páginas, la Historia es abierta y compleja. El fruto de su estudio es el resultado del interés con que nos hayamos acercado a ella según las preocupaciones históricas que hayamos manifestado, mostradas en prejuicios y en la formulación de interrogantes históricos de uno u otro signo. De esta forma, nos encontramos con que el historiador puede en sus obras mostrar una cierta inclinación ideológica a la hora de encontrar en las fuentes la respuesta a sus interrogantes personales, o con que puede dar un determinado ejemplo moral, pero nunca puede permitirse el lujo de hacerlo faltando a la honestidad científica. Así, el historiador puede mostrar una determinada inclinación y puede buscar en sus trabajos una finalidad ideológica o moral, pero la interpretación final que realice de las mismas fuentes no tendría por qué ser partidista, sino objetiva y honesta. Por tanto, el científico de la Historia no debería servir a ninguna idea, pero en caso de mostrar una determinada inclinación ideológica, lo ha de hacer siempre sin dejar de emplear rigurosamente el método y llegando a interpretaciones sólidamente fundamentadas, sean éstas del signo que sean. Ese es su compromiso. En esta línea, el historiador, además, no ha de osar decir algo falso que reafirme su pensamiento o ideología, sino que no ha de callar la verdad aunque ésta no le guste y contravenga sus principios morales o ideales políticos. La manipulación intencional de la Historia no debería ser competencia del historiador. Esa es cuestión de ideólogos y de panfletistas. $\mathrm{Y}$ en demostrar dicha honestidad, el historiador se juega su credibilidad social.

En este terreno en el que nos movemos, entra en juego el último de los valores que debiera regir la ciencia histórica: la objetividad y la racionalidad. Antoine Prost ha dicho que "la historia dice la verdad, pero sus verdades no son absolutas" $"$. A priori puede parecer una contradicción, pero en el fondo no

43 Prost, Antoine. Doce lecciones, p. 284. 
lo es. ¿Por qué? Pues porque como hemos argumentado antes, el historiador ha de ser honesto, y sea cual sea la posición desde la que parta, sean cuales sean las preguntas que se haga y el prejuicio desde el que alce el vuelo de la investigación, ha de emplear rigurosamente el método crítico y, lejos de banderismos de toda clase, ha de dar fiel testimonio de lo que las pruebas o fuentes le dicen. Por tanto, el historiador no tiene permitido ningún margen para tergiversar esa información si hace un buen empleo del método histórico, el cual permite que la documentación y los hechos hablen muchas veces por sí solos. Eso sí, dentro de la heterogeneidad de preguntas que a éstos puedan hacérseles.

La objetividad con que se abordan los estudios y con que se resuelven los problemas históricos que nos planteamos es uno de los aspectos por los que más se ha puesto en entredicho a la Ciencia histórica, a la que se ha arrogado en muchos casos un carácter no científico, debido a la existencia de las posibles diversas interpretaciones que se pueden hacer de unas mismas fuentes. La sociedad se pregunta a este respecto: ¿Cómo puede suceder que el estudio exhaustivo de un mismo documento, sometido a unas reglas críticas concretas, pueda ser interpretado de diferente manera? La respuesta es sencilla: el documento siempre nos habla de aquello que nosotros le hemos preguntado previamente (responda luego o no a las hipótesis de que partíamos). Existe, por tanto, una primacía de las preguntas sobre el documento, que consigue que no podamos hacer siempre una lectura definitiva de un documento concreto mientras no hayamos estudiado dicho documento desde todas las perspectivas posibles. La consecuencia es, pues, que la historia siempre puede rescribirse, por cuanto las preguntas históricas varían a medida que evolucionan las sociedades y las preocupaciones de éstas (se ha dicho comúnmente que cada generación ha de escribir su propia historia $)^{44}$.

\subsection{La difusión social del oficio de historiador}

La desestimación o la estimación social de que venimos hablando también depende de la imagen que el historiador propague de su propia profesión, y del grado de presencia que ocupe en los medios de comunicación, vehículo fundamental de socialización y punto esencial de divulgación histórica.

44 Marisa González de Oleaga nos dice: "De hecho no puede existir un significado original de este o aquel suceso -sea éste un acontecimiento o una acción humana-, toda vez que las posibilidades de relación entre un suceso y sus muchos contextos y temporalidades son infinitas y están abiertas”. En González de Oleaga, Marisa: “¿El fin de los historiadores o el fin de una hegemonía?”. En Sánchez León, Pedro; Izquierdo Martín, Jesús. Fin, p. 158. 
A este respecto, hay que señalar que actualmente, y en líneas generales, los historiadores dan (o se les da la oportunidad de dar) una muy escasa proyección social de su trabajo. Este problema puede observarse bajo una doble óptica: por un lado, bajo factores externos, y por otro, bajo un factor interno.

Como primer factor externo nos encontramos con el problema de que aún hoy día los historiadores tienen una reducida presencia pública en medios de comunicación. En este sentido, resulta desolador que las cadenas de televisión o las emisoras de radio (no tanto medios editoriales y periodísticos) establezcan debates históricos y no llamen directamente a los profesionales de la Historia (profesores académicos o investigadores) para que formen parte de ese debate. En este terreno, el historiador ha de encontrar su espacio dentro de los medios de comunicación, para de este modo divulgar la Historia con la objetividad y minuciosidad que casi siempre les falta a aquellos medios y comentaristas que últimamente se arrogan la potestad del conocimiento histórico en unos medios de comunicación que, a tenor de la tensión y la agresividad del debate, resultan cada vez más ideologizados. Por ello, el historiador ha de combatir esa imagen cada vez más extendida de la Historia como terreno ideologizable, y de la Historia como materia dominada por una suerte de opiniones subjetivas y relativas, porque de lo contrario, sea cual sea el esfuerzo que haga por ser un investigador imparcial y honesto, seguirá contemplando ese cuestionamiento social del que es víctima muchas veces injustamente. En esta vía, el historiador ha de distanciarse y ha de desdeñar directamente los discursos históricos que tengan poco de científico, de sólidos y de bienintencionados (científicamente hablando).

El segundo factor externo tiene que ver con el escaso nivel de concienciación que se ofrece a la sociedad acerca de la importancia de los beneficios que la labor investigadora y profesional en el campo de la Historia, puede aportar a la misma sociedad. Esta cuestión tiene que ver con los problemas ya planteados sobre la función social del historiador y del intelectual. Pero cabe apuntar aquí que el problema a que se enfrentan los historiadores en este sentido es amplio y, en cierto modo, una cuestión complicada y espinosa. Entre otras razones porque el historiador siempre parece verse obligado a justificar que no pueda dar respuestas prácticas a aquellos problemas que ocupan materialmente nuestra vida cotidiana; porque parece que tenga siempre que justificar que no pueda dar al ciudadano herramientas con las que se pueda solucionar nuestra vida material; y también porque siempre parece que tenga que justificar su profesión por ser, para 
una sociedad ávida de beneficios tangibles, una profesión de "segunda". Por tanto, estamos ante un problema que influye en la desestimación que tiene nuestra profesión, ante un problema por el cual los historiadores en muchos casos se ven obligados a justificarse, argumentando los beneficios inmateriales, imperceptibles muchas veces, que reporta su profesión, que tiene que ver, como ya hemos dicho, con la creación de discursos capaces de penetrar en la humanidad en un proceso lento, de transformación de valores e ideas, que acaba modificando su fisonomía espiritual e incluso, en muchos casos, organizativa.

Finalmente, nos encontramos con otra cuestión que tiene bastante que ver con el problema de la difusión social del oficio de historiador, pero que constituye propiamente un factor interno, del que deberíamos hacer más autocrítica. Nos estamos refiriendo a un problema que afecta al grado de concienciación que sobre la importancia social de la profesión histórica se da a aquellas personas que quieren asumir en el futuro la responsabilidad de hacer evolucionar la ciencia histórica, es decir, a los estudiantes. En líneas generales, puede decirse que existe un cierto déficit en cuanto a la implicación de los profesionales de la Historia a la hora de concienciar a los mismos universitarios acerca de la importancia de la labor social que éstos pueden desarrollar. Así, entiendo que existe una carencia en el interior de las aulas, donde resulta algo deficiente la enseñanza sobre teoría de la Historia (explicación de los fundamentos generales acerca de la naturaleza de lo histórico), sobre teoría de la lógica, o sobre teoría de la argumentación y de la comprensión de la Historia ${ }^{45}$. Pasamos a analizar esta cuestión en el punto siguiente, intentando acercarnos al problema que plantean, en este sentido, los planes de estudio desarrollados bajo el Plan de Bolonia, y poniendo a la Universidad de Salamanca como ejemplo ilustrativo.

\subsection{El estudiante universitario y la Historia como disciplina} socialmente cuestionada. Un estudio de caso: Salamanca.

Veamos brevemente, y como punto final, lo que ocurre en las aulas, la imagen que se proyecta de la Historia, la formación que recibimos y las deficiencias que se observan en la Universidad actual de cara a la comprensión de nuestra área. Lo vamos a hacer tomando como ejemplo la licenciaturagrado de Historia en la Universidad de Salamanca.

45 Afirma Julio Aróstegui que "Sin una cierta preparación teórica y sin una práctica metodológica que no se limite a rutinas no es posible la aparición de buenos historiadores". Aróstegui, Julio. La Investigación histórica, p. 18. 
¿Qué deficiencias presentan nuestros planes de estudio universitarios respecto del tema que nos ocupa? Para responder a esa pregunta, lo primero que deberíamos hacer sería interrogarnos acerca de cuál es la enseñanza que recibimos: qué se nos dice sobre la utilidad y fines sociales de la Historia, y qué se nos enseña respecto del método de investigación histórico. Por tanto, no hablaremos del grado de conocimientos típicamente históricos, sino metodológicos y teóricos, que son los que a la postre tienen estrecha relación con la legitimidad social de la Historia como profesión. Para ello, vamos a partir, de la comparación entre el antiguo Plan de licenciatura del año 2000 y el nuevo Plan de Convergencia Europeo.

A diferencia de otras titulaciones (que lo hacen en menores proporciones), la carrera de Historia divide en buena medida sus asignaturas y créditos entre materias troncales y materias optativas. En el Plan antiguo teníamos una serie de asignaturas que tendían al estudio de la historia de la historiografía, así como al estudio de ciertos instrumentos metodológicos. Entre esas asignaturas destacaban:

1. Materias troncales (34 créditos sobre 144 cursados):

\subsection{Arqueología}

1.2 Paleografía y Diplomática. Epigrafía y numismática.

1.3 Métodos y técnicas de investigación histórica

1.4 Tendencias historiográficas actuales

2. Materias optativas y materias optativas afines (hasta 126 créditos sobre 126 cursados y 414 elegibles $\left.{ }^{46}\right)$ :

\subsection{Gestión del Patrimonio Arqueológico}

2.2 Museología y Patrimonio

2.3 Historia de la Técnica

2.4 Últimas tendencias en Arqueología

46 Entendemos por "cursados" el número total de créditos que debemos cursar a lo largo de la carrera, y por "elegibles" el número total de créditos que suman el total de posibles asignaturas optativas a elegir dentro del Plan de estudios. 
2.5 Técnicas arqueológicas de campo

2.6 Últimas tendencias en Prehistoria

2.7 Metodología de la Prehistoria

2.8 Tipología y tecnología del instrumental prehistórico

2.9 Fuentes y métodos de la Historia Antigua

2.10 Epigrafía y Numismática

2.11 Numismática de la Península Ibérica

2.12 Introducción a la lengua latina

2.13 Lengua y cultura griega

2.14 Últimas tendencias en Historia Medieval

2.15 Paleografía Medieval

2.16 Espacios y tiempos medievales e instrumentos para su estudio

2.17 Textos y documentos de la Historia Moderna

2.18 Paleografía Moderna

2.19 Últimas tendencias en Historia Contemporánea

2.20 Antropología social

\subsection{Introducción a la Economía}

Como se puede observar, son varias las asignaturas que nos hablan del método histórico ${ }^{47}$, especialmente para aquellas áreas más vinculadas a la Arqueología y la Prehistoria. A medida que nos acercamos a la Edad Contemporánea, la formación metodológica -cuantitativamente hablandodisminuye. De modo que, salvando en cierta medida esas primeras especialidades, la enseñanza de teoría y método queda, en mi opinión, algo desfavorecida. Además, creo que en la formación recibida se echa en falta una atención mayor al aspecto práctico, a la formación técnica, en el que se profundiza poco (especialmente en las troncales).

En primer lugar, en lo referido al terreno teórico ${ }^{48}$ se ha estudiado

47 Pocas en cuanto a lo que se refiere a asignaturas troncales.

48 No hablo aquí de la formación sobre la evolución de las diferentes civilizaciones a lo 306 
ligeramente el concepto que históricamente se ha tenido de la Historia como disciplina académica. Pero, en cambio, ha faltado la celebración de debates acerca de la deontología de la Historia, sobre su significación social, sobre los criterios con que se enjuicia la propia producción historiográfica por parte de la comunidad de historiadores, y sobre las capacidades y habilidades cognitivas que el estudiante de Historia adquiere en su formación universitaria (donde participen a modo de seminario alumnos y profesores, los cuales podrían hablar de su propia experiencia personal). Ha faltado también una lectura y un estudio más exhaustivo de las principales obras sobre método y teoría de la investigación histórica de cara a la celebración de dichos debates. Y no ha habido tampoco un estudio y reflexión seria y profunda sobre sociología del conocimiento como construcción social de la realidad; al igual que tampoco se ha dado una discusión rigurosa (siempre bien orientada por el profesorado) sobre el cuestionamiento de la historia como ciencia y sobre el concepto de "Filosofía de la historia", etc.

Por otro lado, en lo tocante al terreno metodológico, lo que se ha estudiado fundamentalmente es la teoría sobre la que se ha asentado el método de las diferentes tendencias o escuelas historiográficas aparecidas hasta la actualidad. Pero no se han realizado apenas ejercicios en los que se haya puesto en práctica las diversas aplicaciones que puedan tener esos métodos o concepciones metodológicas ${ }^{49}$. No ignoro que la falta de tiempo y la dificultad y amplitud de la actividad son factores que llevan a que esos ejercicios no se acaben llevando a la práctica. Pero, la realidad es que, al final, todas las herramientas, instrumentos y técnicas de investigación se acaban adquiriendo con la realización de un programa de doctorado, lo cual hace que el estudiante que no cursa estudios de Tercer Ciclo -y desarrolle un trabajo de investigación- acabe teniendo una idea bastante deficiente sobre la legitimidad que los métodos de investigación histórica dan a nuestra disciplina.

Visto el Plan antiguo... ¿ ¿Supone, en este sentido, un avance el nuevo Plan implantado, el famoso Plan Bolonia que quiere significar una apuesta

largo de las diferentes etapas históricas.

49 Por ejemplo, no se realizan discusiones de artículos o de recensiones críticas de libros. 
mayor en la Universidad por la práctica científica sobre la teoría, una apuesta por la enseñanza como aprendizaje? ${ }^{50}$ Mucho me temo que no. Veamos por qué.

Si comparamos las asignaturas ofrecidas al alumnado en las guías de los diferentes planes de estudio, vemos que el nuevo Plan ha traído consigo la aparición de nuevas asignaturas (que tienden hacia el fomento de la interdisciplinariedad en la investigación histórica) y la desaparición de muchísimas otras (muy relacionadas con el estudio de técnicas y métodos de investigación). Es decir, se ha producido un acercamiento a las ciencias sociales que complementan el estudio de la Historia pero, a cambio, se ha prescindido de asignaturas que nos enseñan los fundamentos de la misma investigación histórica. ¿Qué asignaturas son esas? Tenemos:

1. Materias troncales (18 créditos en total sobre 186 cursados):

\title{
1.1 Arqueología I
}

\subsection{Arqueología II}

1.3 Paleografía y Diplomática. Epigrafía y Numismática

\begin{abstract}
2. Materias optativas (96 créditos elegibles en total sobre 54 cursados):
\end{abstract}

2.1 Patrimonio arqueológico, etnológico y museológico

2.2 Paleografía medieval e Historia de la Escritura

2.3 Paleografía Española Moderna

2.4 Epigrafía y Numismática

2.5 Lengua clásica: Latín para historiadores

2.6 Idioma moderno: Inglés académico

50 Hemos hablado de la falta en el Plan antiguo de debates y seminarios. Hasta la fecha el modelo pedagógico en la Universidad ha seguido siendo el comúnmente denominado como "clase magistral". Un modelo típicamente monologuista. El nuevo Plan Bolonia, entendido como Plan que fomenta la enseñanza como aprendizaje, debería hacer evolucionar ese modelo pedagógico hacia un modelo dialógico, donde predomine la discusión y el debate. 


\subsection{Introducción a la Sociología}

2.8 Introducción a la Antropología

2.9 Introducción a la Ciencia Política

2.10 Historia y fundamentos de Economía

2.11 Historia de la Filosofía

\subsection{Informática aplicada}

Nos encontramos, pues, con un Plan que conserva la Arqueología como asignatura troncal (ampliada a dos), que mantiene la asignatura de "Paleografía y Diplomática. Epigrafía y Numismática", pero que, a cambio, prescinde totalmente de las dos asignaturas que mayor énfasis y atención ponían en la cuestión del método histórico (especialmente la de "Métodos y técnicas de investigación histórica").

Aparte, y como vemos, incorpora asignaturas a modo de introducción a otras disciplinas propias de las Ciencias Sociales (Sociología, Antropología, Politología, Economía, Filosofía). No sabemos aún cuáles van a ser los contenidos de dichas asignaturas, que empezarán a impartirse a partir del próximo curso; y no sabemos, pues, si incidirán en la enseñanza del método utilizado en las disciplinas que analizan (que sería lo más aconsejable), o si simplemente se limitarán a describir de alguna forma el estado de la cuestión acerca de los estudios que realizan dichas ciencias o de la implicación e importancia que tienen en el conocimiento de la Historia (que es lo más probable).

El nuevo Plan incorpora además tres asignaturas que pueden tener -si se imparten con rigor- notable importancia: me refiero a la asignatura de "Inglés académico", a la de "Informática aplicada", y a la parte de una asignatura que hace referencia a la "Historia de la Escritura". Este último aspecto me parece interesante por cuanto el estudiante de Historia que ha salido hasta la actualidad de las aulas, lo ha hecho casi siempre sin haber adquirido una especial habilidad en el uso del lenguaje (fundamental a la hora de escribir, hablar y argumentar; los cuales son aspectos que están en la base de nuestra disciplina como ciencia social). Me temo que la asignatura (esencialmente a razón del lugar en que está encuadrada) no irá encaminada a dotar al estudiante de un conocimiento sobre las técnicas de escritura de la Historia. Y me temo que nada nos va a hablar sobre cuestiones tan importantes como son la del estilo, la de la gramática, la semántica, la sintaxis, 
la estructura, las normas de citación bibliográficas, la argumentación, etc.

Finalmente diremos que el nuevo Plan elimina numerosas materias optativas de notable alcance en lo que se refiere a la metodología histórica. Así, se eliminan las asignaturas que nos hablan sobre tendencias historiográficas para todas las edades históricas, así como asignaturas sobre fuentes, métodos y técnicas de investigación histórica. Sólo hace falta echar un vistazo a los cambios realizados para darse cuenta de cuáles son exactamente las asignaturas que a este respecto se han suprimido. $Y$ en ese sentido, es el área de la Arqueología y la Prehistoria quienes ahora más se resienten.

En síntesis, consideramos que los planes de estudio diseñados bajo el EEES no parecen a primera vista que vayan a solucionar el problema que nos venimos planteando. Espero equivocarme, pero en principio da la impresión de que el estudiante no va a salir con una idea bastante más clara de qué es lo que hace y para qué sirve lo que estudia. No parece que el estudiante, tan preocupado siempre por encontrar en el título universitario una credencial de salida laboral, vaya a poder responder mejor a esa pregunta de: "Historia ¿Para qué?”. Entre otras razones, porque quizá falte tensión o vocación en un alumnado que muchas veces muestra poco interés. Pero también porque seguramente la Universidad nos habla bastante poco de lo que somos como para que realmente salgamos convencidos de lo que sería lógico y esperable que hiciéramos.

\section{CONCLUSIÓN}

Hemos visto hasta ahora que la desestimación o la estimación social que pueda sufrir nuestra disciplina depende de varios factores: el papel que ejerza el intelectual en la sociedad, el rigor con que se aplique el método histórico, el sobrepeso que puedan tener nuestra ideología particular o nuestros compromisos sociales y morales en la investigación que llevemos a cabo, los valores que debieran regir la ciencia histórica, la difusión social que el historiador dé de su propia profesión, o el grado de concienciación que se dé a los estudiantes de Historia sobre la importancia social de la Historia a través de los planes de estudio.

Consideramos que los puntos anteriormente expuestos pueden reforzar la imagen de la Historia como una disciplina honesta, imparcial, crítica, racional y objetiva. No obstante, entendemos que el fortalecimiento 
de esa imagen pasa por intensificar la presencia de los historiadores en los medios de comunicación en lo que a los tan recurridos debates históricos en la actualidad se refiere. $Y$ también por perfeccionar nuestros planes de estudios, para que el estudiante que sale de las aulas tenga un mejor concepto sobre la deontología de nuestra disciplina y pueda contestar sin demasiados problemas a esa pregunta tan típica de: "Historia, ¿para qué?".

En tanto remontamos el vuelo, preguntémonos si no resulta paradójico que la historia como materia de conocimiento goce socialmente de tanto reconocimiento, y que los historiadores como profesionales ni gocemos de igual predicamento ni nos encontremos muchas veces en primera línea de la opinión pública. Preguntémonos si no sorprende que se abra en ocasiones una brecha considerable entre lo que podríamos denominar "historia popular" con respecto a la historia puramente académica, y que algunos estudiosos de la Historia a otro nivel (periodistas, novelistas, etc.) tengan mayor espacio en la difusión del conocimiento histórico ${ }^{51}$. Y reflexionemos detenidamente sobre este último comentario:

"A pesar de su formación como bistoriadores profesionales, no se ha logrado (o al menos no de un modo amplio) que la sociedad reconozca en ellos valores que la bistoria académica reclama como propios, tales como la seriedad en la crítica documental, el dominio del orden del discurso, la búsqueda del juicio sobrio (o la objetividad, si se quiere), la capacidad de interpretar fenómenos complejos, el conocimiento panorámico de realidades extensas, etc. Esto puede calificarse como una dejación de funciones: el historiador universitario no es capaz de imprimir en los estudiantes aquellas caracteristicas que lo definen profesionalmente ${ }^{\text {"52. }}$.

51 Aunque como señala Prost, "la vanguardia de la disciplina no suele aparecer en esas prácticas". Prost, Antoine. Doce lecciones, p. 100. A veces puede el juicio mediático al juicio científico.

52 Castro Ibaseta,J.; Martínez Bermejo, S.: “Monólogo. Educación, tradición y comunicación en la historiografía académica española”. En Sánchez León, Pedro; Izquierdo Martín, Jesús. Fin, p. 241. 
